\title{
Studying the process of freons mixture separation on a structured packing Sultzer $500 \mathrm{X}$
}

\author{
Aleksandr Pavlenko ${ }^{1}$, Vladimir Zhukov ${ }^{1,{ }^{*}}$, Nikolay Pecherkin ${ }^{1}$, Ekaterina Slesareva ${ }^{1}$, \\ Christo Boyadjiev ${ }^{2}$, and Daniela Dzhonova-Atanasova ${ }^{2}$ \\ ${ }^{1}$ Kutateladze Institute of Thermophysics SB RAS, Novosibirsk, Russia \\ ${ }^{2}$ Institute of Chemical Engineering, Bulgarian Academy of Sciences, Bulgaria
}

\begin{abstract}
Structured packings are widely used in distillation columns to separate various types of mixtures. These packings have an ordered structure, which ensures more uniform conditions for interaction of counter-current flows of liquid and vapor than in the random packings and have a small hydraulic resistance. Nevertheless, in columns with a diameter of more than $0.5 \mathrm{~m}$, formation of large-scale non-uniformity in distribution of liquid and vapor flow parameters over the packing crosssection is observed. In this work, experimental data on formation of largescale non-uniformity in the temperature field over the cross-section of the Sulzer 500X packing, as well as on the efficiency of mixture separation and the pressure drop across the packing were obtained. The experiments were carried out with separation of R114/R21 freon mixture on a 10-layer structured packing Sulzer 500X with a diameter of $0.6 \mathrm{~m}$ and a height of $2.2 \mathrm{~m}$. Experimental data were compared with the results obtained earlier for a structured packing Mellapack 350.Y with a diameter of $0.9 \mathrm{~m}$ and a height of $2.1 \mathrm{~m}$. The presented experimental data will be used to construct and verify a new model of mass transfer and efficiency of mixture separation in the large-scale distillation packed columns.
\end{abstract}

\section{Introduction}

Thermal separation of liquid mixtures into their constituent parts is most often implemented in the processes of distillation and rectification. Rectification and distillation are widely used in the chemical, oil refining, pharmaceutical, and food industries and laboratory practice. Rectification columns, whose efficiency depends on various parameters, are widely used to perform rectification in industry [1-4]. One of the important tasks of various studies is organization of the most uniform distribution of countercurrent flows of vapor and liquid film on the packing surface over the column cross-section. To achieve this goal and thereby to increase the efficiency of distillation column, structured packings of various shapes are being developed and used more and more [5-10], which allow organizing a fairly uniform distribution of liquid and vapor flows. However, in largescale distillation columns, it is necessary to pay attention to possible formation of zones of temperature field irregularity in the column cross-section, whose dimensions are

*Corresponding author: zhukov@itp.nsc.ru 
commensurate with the column diameter [6]. This work was carried out within the framework of the joint Russian-Bulgarian research project aimed at developing methods for modeling the processes of mixture separation in large-scale industrial equipment. This work forms part of a series of studies aimed at obtaining experimental data on separation efficiency in large-scale columns and dynamics of formation of large-scale non-uniformity in distribution of local parameters of countercurrent vapor and liquid flows through a structured packing during mixture separation. The studies on a structured packing Mellapack 350.Y with a diameter of $0.9 \mathrm{~m}$ and a height of $2.1 \mathrm{~m}$ were carried out within the framework of this project [11 - 13]. This work presents similar data obtained in distillation experiments on a Sulzer 500X structured packing with a diameter of $0.6 \mathrm{~m}$ and a height of $2.2 \mathrm{~m}$.

\section{Set-up and method description}

The experiments were carried out on a large-scale model of a distillation column, specially designed for studying the processes of hydrodynamics and mass transfer on structured packing. The setup was designed to operate on a mixture of R114/R21 freons. This mixture is specially selected for simulating the processes of distillation of cryogenic mixtures at ambient temperatures. A detailed description of the setup and individual principal units is given in $[6,14]$. The design of setup allows research on the structured packings with a diameter of up to $0.9 \mathrm{~m}$ and a height of up to $4 \mathrm{~m}$. The packing of a $0.9-\mathrm{m}$ diameter is mounted in the cylindrical body of the column, and for the packing of a different diameter ( $0.6 \mathrm{~m}$ in these studies) and the packing of non-circular geometry, special inserts are made that are mounted in the main body of the column [15]. The test setup is used to investigate both the integral characteristics of separation processes, such as separation efficiency and pressure drop across the packing, and the local characteristics of liquid and vapor flows over the column cross-section (distribution of liquid flow density, temperature distribution inside the packing in different column cross-sections, etc.). Distribution of the density of liquid flowing down the packing and distribution of the density of liquid flowing down the column wall are measured by the flow meters, specially developed by the team of the authors and installed on a radial two-coordinate device scanning the column cross-section according to a given program [16]. To measure temperature distribution inside the packing in various cross-sections of the column, a measuring complex was made [17], which allows measuring the temperature in three column cross-sections at 16 points of each cross-section and online displaying the temperature fields of each cross-section on the monitor. In each of three cross-sections, the temperature sensors are evenly distributed. The resolution in measuring the temperature distribution is $0.01{ }^{\circ} \mathrm{C}$, the measurement accuracy is $0.1^{\circ} \mathrm{C}$. Three cross-sections, where the sensors were installed in these experiments, were located at a distance of 440,1100 , and $1680 \mathrm{~mm}$ from the packing bottom.

In the experiments, we used a structured packing Sulzer 500X with a diameter of $0.6 \mathrm{~m}$ and a height of $2.2 \mathrm{~m}$ (10 layers). The packing was irrigated using a liquid distributor with a diameter of $850 \mathrm{~mm}$ with a rectangular drip point pattern. The distance between the rows of nozzles was $99 \mathrm{~mm}$ and between the nozzles it was $22 \mathrm{~mm}$. The nozzles were mounted in the central part of the liquid distributor bottom. The total number of drip points was 121 . The height of a cylindrical vessel of the liquid distributor was $500 \mathrm{~mm}$. Between the rows of nozzles there were the rectangular tubes (vapor passages) designed to pass a countercurrent vapor flow through the liquid distributor. The layout of nozzles and tubes for the passage of vapor at the bottom of liquid distributor is shown in Fig. 1 . 


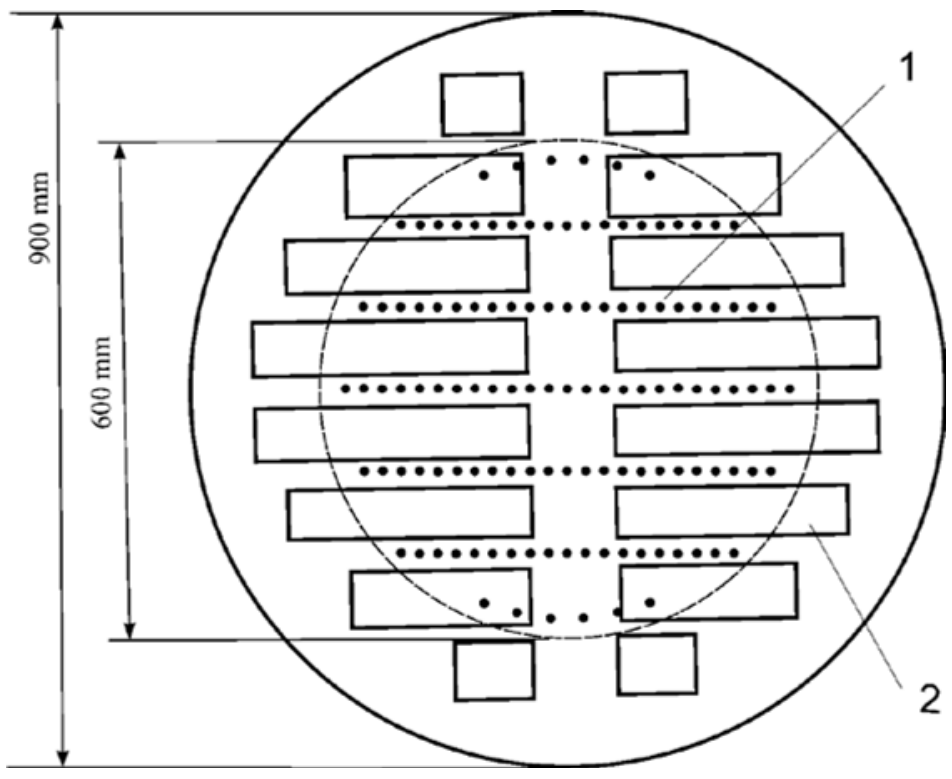

Fig 1. Layout of irrigating nozzles (1) and tubes for the counter-current vapor flow (2) on the liquid distributor bottom.

\section{Results and discussions}

The experiments were carried out under conditions of complete reflux at a pressure of 0.3 $\mathrm{MPa}$. Under these conditions, the mixture temperature in the bottom part of the column was $40.5^{\circ} \mathrm{C}$, and in the top part it was $(34-35)^{\circ} \mathrm{C}$. The column-average vapor velocities $U_{\text {vapor }}$ were within $(0.27-0.75) \mathrm{m} / \mathrm{s}$, and this corresponded to superficial vapor velocity $0.029<$ $K_{\mathrm{v}}<0.081 \mathrm{~m} / \mathrm{s}$, determined from relation (1)

$$
K_{v}=U_{\text {vapor }} \sqrt{\frac{\rho_{\text {vapor }}}{\rho_{\text {liquid }}-\rho_{\text {vapor }}}} .
$$

Here $\rho_{\text {liquid }}$ and $\rho_{\text {vapor }}$ are the densities of liquid and vapor phases, respectively. It was shown that while reaching the stationary separation regime, a large-scale irregularity of temperature distribution over the packing cross-section was formed. A diagram of changes in local temperatures in the middle packing cross-section is shown in Fig. 2 for the average vapor velocities along the column of 0.37 and $0.72 \mathrm{~m} / \mathrm{s}\left(K_{\mathrm{v}}=0.042\right.$ and $0.078 \mathrm{~m} / \mathrm{s}$, respectively).

As it can be seen in the diagrams, at the initial stage, the temperature distribution over the column cross-section is fairly uniform. Large-scale irregularity of temperature distribution over the packing cross-section is formed while the column reaches the stationary operation regime. The process of irregularity formation at two values of vapor velocity $(0.37$ and $0.72 \mathrm{~m} / \mathrm{s}$, respectively) occurs in a similar way. Within (10-15) minutes, the uniform temperature field in the packing cross-section transforms into a stable largescale irregularity with diametrically located areas of minimum and maximum temperatures. The difference in the minimum and maximum temperatures in the middle cross-section of the packing is (4-5) $\mathrm{K}$ with a total temperature difference along the packing height of (5-6) $\mathrm{K}$. Formation of large-scale non-uniformity in temperature distribution on the Mellapack 350 .Y packing of a $0.9-\mathrm{m}$ diameter at vapor velocities of 0.15 and $0.26 \mathrm{~m} / \mathrm{s}$ is similar to $[12,13]$. 


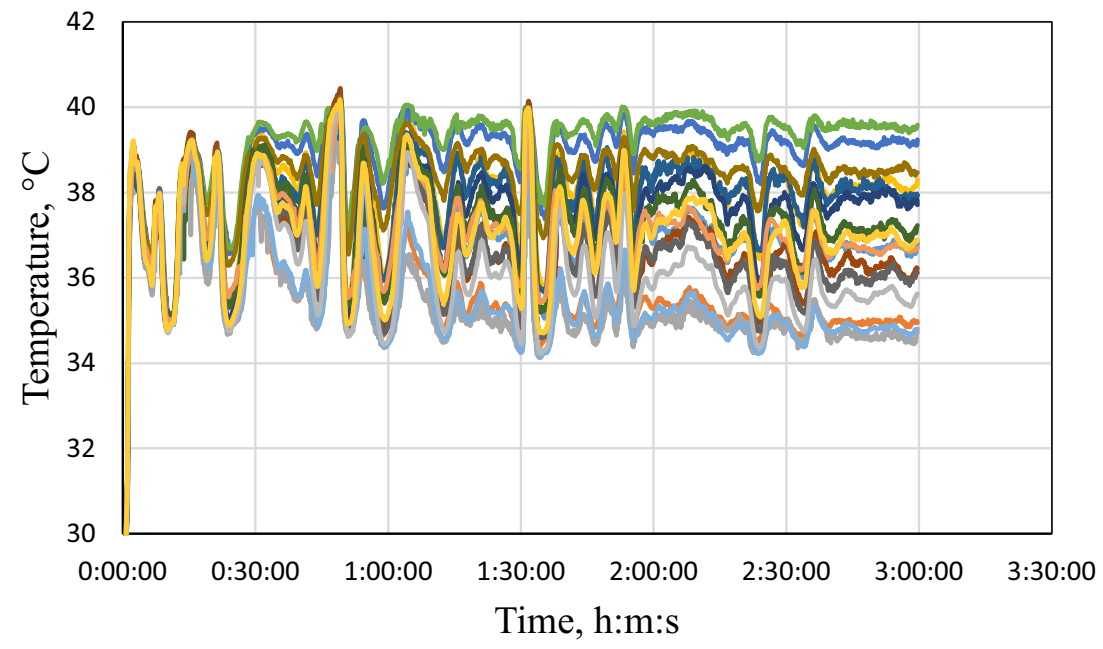

(a)

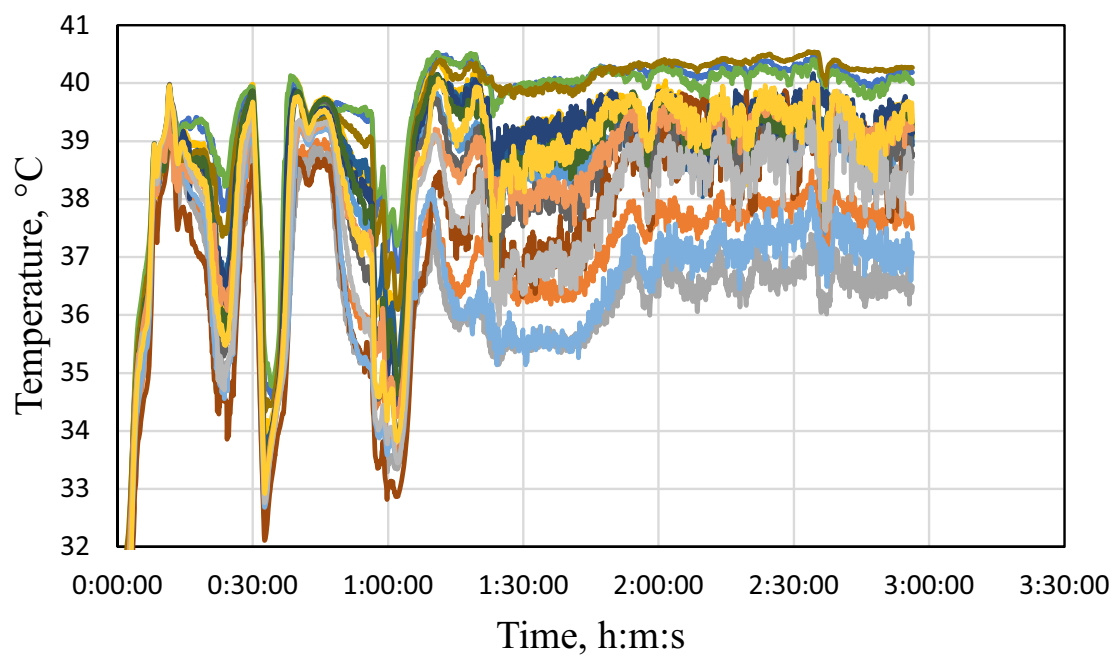

(b)

Fig. 2. Diagram of a change in local temperatures in the middle $(h=1.1 \mathrm{~m})$ cross-section of Sulzer $500 \mathrm{X}$ packing while achieving the stationary regime of column operation. $a-K_{\mathrm{v}}=0.042 \mathrm{~m} / \mathrm{s} ; b-$ $K_{\mathrm{v}}=0.078 \mathrm{~m} / \mathrm{s}$.

Hydrodynamics of the gas (vapor) and liquid phases in counter-flow columns with packing is characterized by the presence of a liquid layer on the column wall, even when the contact surface of the packing with the wall is small [18]. The liquid that flows from the edges of corrugated sheets of the packing to the column wall cannot completely return back into the packing and flows downward, gradually increasing its thickness until the equal flow of liquid in both directions (to the wall and from the wall) is achieved. In counter-flow columns with packing, gas (vapor) contacts with a liquid layer on the column wall. A theoretical analysis of hydrodynamics of two-phase flows [19] shows that the motion of gas before reaching critical values does not affect the flow of liquid; however, the flow of liquid in films of considerable thickness (with high velocities at the free boundary) affects 
the motion of gas significantly, since at the interface the velocities of gas and liquid must be equal. Thus, in local zones near the column wall, gas (vapor) can move downward, i.e. a large-scale circulation contour (stagnant zone) with a characteristic length equal to the packing height is formed. As a result, the presence of a sufficiently thick liquid layer on the column wall creates radial non-uniformity of velocities in two phases, which leads to a decrease in the rate of interphase mass transfer. When organizing such a circulation contour of liquid and vapor flows, as a consequence, at different values of vapor flow temperature along the radius near the column wall, a corresponding circulation temperature contour is also formed.

To study hydrodynamics of interaction of a counter-current vapor flow with the jets of irrigation liquid spreading over the upper packing layer in the region of high vapor velocities, a special coordinate device with the installed hot-wire anemometer was made. These studies are currently at the stage of approbation and measurement technique testing.

The data on the efficiency of mixture separation and pressure drop across the structured Sulzer 500X packing are shown in Fig. 3 in comparison with the corresponding experimental data for the structured Mellapack 350.Y packing [13]. The packing heights are 2200 and $2100 \mathrm{~mm}$, respectively.

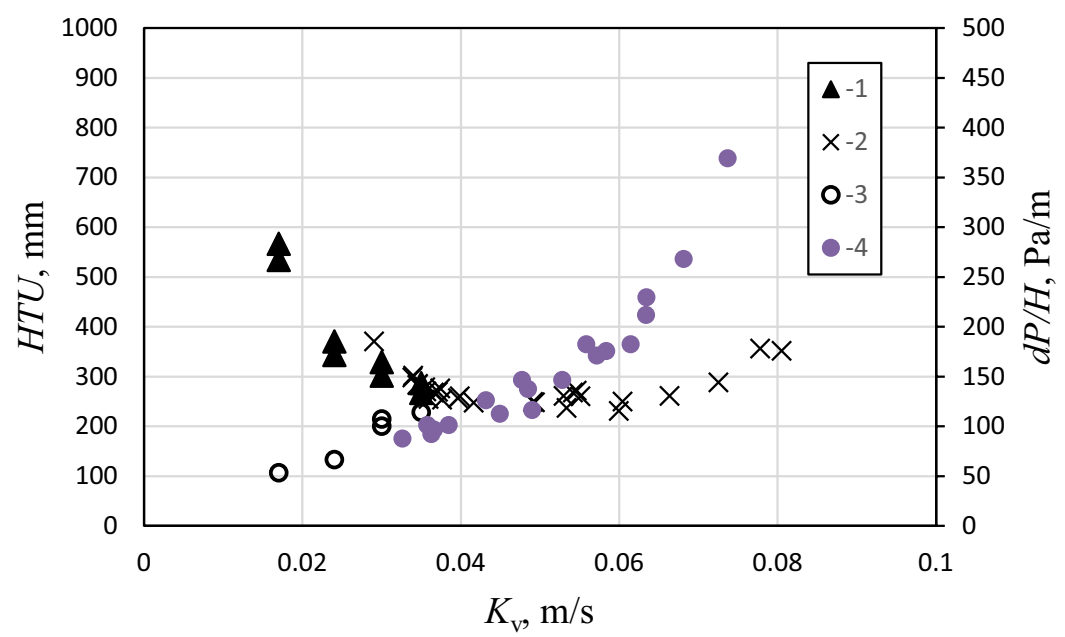

Fig. 3. Efficiency of mixture separation $(H T U)$ and pressure drop on the structured Mellapack 350.Y [13] and Sulzer 500X packing. 1 - HTU Mellapack 350.Y [13]; 2 - HTU Sulzer 500X; 3, 4 - pressure drop on the packings, respectively.

The packing corrugation angles differ, so a packing with a shallower corrugation (Mellapack 350.Y) has a higher pressure drop per packing height unit (points 3). The separation efficiency in the area of identical $K_{\mathrm{v}}$ values on the Mellapack 350.Y packing is slightly higher than that on the Sulzer 500X packing. Since the presence of a large-scale non-uniformity of temperature distribution over the packing cross-section is observed over the entire range of the studied values of superficial vapor velocity, a significant decrease in the efficiency of mixture separation in the region of small $K_{\mathrm{v}}$ values is apparently associated with the presence of under-/weakly irrigated regions of both packings. Underirrigated areas of packing can be formed during jet irrigation with a given density as a result of uneven distribution of liquid during film flow over the complex surface of structured packing, also due to significant accumulation of liquid on the column wall.

Simulation of liquid spreading over the packing surface is proposed within the framework of the model based on computational fluid dynamics (CFD) [20]. The largescale flow non-uniformity in random packings are successfully simulated by diffusion 
models. Such a model is applied, e.g. for predicting liquid spreading in open-structure random packings [21]. Unlike random packings, the corrugated structured packings determine strong preferential flow directions, which cannot be predicted by the diffusion models. Therefore a CFD-based approach is offered to model the anisotropic properties of corrugated structured packings [22]. Based on these studies, our efforts are directed towards development of a CFD model of a counter-current two-phase flow, proper for structured packings (as well as random packings). The experimental data obtained in this work and in $[12,13,23]$ are currently used for the development and verification of the proposed model.

\section{Conclusions}

Experimental data on the dynamics of formation of a large-scale temperature field irregularity in the cross-section of a distillation column with the Sulzer 500X packing with a diameter of $0.6 \mathrm{~m}$ and a height of $2.2 \mathrm{~m}$ were obtained and compared with previous results obtained for the Mellapack 350.Y packing with a diameter of $0.9 \mathrm{~m}$. The temperature field non-uniformity in the middle packing cross-section is (4-5) $\mathrm{K}$ in the range of the studied vapor velocities along the column of $(0.15-0.81) \mathrm{m} / \mathrm{s}$.

Experimental data on separation efficiency and pressure drop on the Sulzer 500X packing $2.2 \mathrm{~m}$ high were obtained and compared with the previously obtained data on the Mellapack 350.Y packing $2.1 \mathrm{~m}$ high. The Sulzer 500X packing is characterized by a lower pressure drop, but the Mellapack 350.Y packing has slightly higher separation efficiency in the region of low values of vapor velocities $\left(K_{\mathrm{v}}<0.035 \mathrm{~m} / \mathrm{s}\right)$.

The obtained experimental data are an important and necessary experimental material used in the development and verification of the model of hydrodynamics and mass transfer in large-scale distillation packed columns developed within the framework of a joint project.

\section{Acknowledgment}

This research has been performed at Kutateladze Institute of Thermophysics SB RAS with the support of the Russian Foundation for Basic Research contract No. 19-58-18004Bulgaria_a and National Science Fund of Bulgaria, contract No. KP 06 RUSIA3/27.09. 2019 (block on investigation of the efficiency of separation, pressure drop and distribution of local flow parameters in distillation columns with structured packings of various shapes), the study and development of experimental methods for local flow parameter diagnostics at the separation of mixtures in large-scale distillation columns with packings were carried out under the state contract with IT SB RAS (No. 121031800216-1).

\section{References}

1. N. Kolev, Elsevier Science 708 (2006)

2. J. Feldman, M. Myles, I. Wender, M. Orchin, Ind. Eng. Chem. 41(5), 1032 (1949)

3. R. Billet, M. Schultes, Chem. Eng. Technol. 16(1), 1 (1993)

4. V. Bessoua, D. Rouzineau, M. Prevost, F. Abbe, Ch. Dumont, J-P. Maumus, M. Meyer, Chem. Engin. Sci. 65(16), 4855 (2010)

5. A.N. Pavlenko, N.I. Pecherkin, V.Yu. Chekhovich, V.E. Zhukov, S. Sunder, P. Houghton, Theoretical Foundations of Chem. Eng. 43, 1 (2009)

6. A.N. Pavlenko, V.E. Zhukov, N.I. Pecherkin, V.Yu. Chekhovich, O.A. Volodin, A. Shilkin, C. Grossmann, AIChEJ 60(2), 690 (2014) 
7. A.N. Pavlenko, X. Li, V.E. Zhukov, N.I. Pecherkin, O.A. Volodin, A.S. Surtaev, X. Gao, L. Zhang, H. Sui, H. Li, J. of Eng. Thermoph. 24, 210 (2015)

8. S.J. Gerke, J.U. Repke, Chem. Eng. Research and Design 147, 634 (2019)

9. L.S. Tan, A.M. Shariff, K.K. Lau, T. Tsuji, Materials today: proceedings 5(10), 22085 (2018)

10. R.K. Singh, J.E. Galvin, X. Sun, Chem. Eng. J. 353, 949 (2018)

11. A.N. Pavlenko, V.E. Zhukov, N.I. Pecherkin, E.Y. Slesareva, J. of Eng. Thermoph. 29(2), 195 (2020)

12. A.N. Pavlenko, V.E. Zhukov, E.Y. Slesareva, D. Dzhonova-Atanasova, P. PopovaKrumova, Bulgarian Chem. Communications 52(F), 42 (2020)

13. A.N. Pavlenko, V.E. Zhukov, E.Y. Slesareva, Chr. Boyadjiev, D. DzhonovaAtanasova, J. of Phys.: Conf. Series 1614(012067), 1 (2020)

14. A.N. Pavlenko, N.I. Pecherkin, V.E. Zhukov, V.Yu. Chekhovich, A.F. Serov, A.D. Nazarov, S. Sunder, P. Houghton, Theoretical Foundations of Chem. Eng. 40(4), 329 (2006)

15. A.N. Pavlenko, N.I. Pecherkin, V.E. Zhukov, A.D. Nazarov, G. Meski, P. Houghton, Chem. Eng. and Processing 133, 211 (2018)

16. A.F. Serov, A.N. Pavlenko, N.I. Pecherkin, A.D. Nazarov, S.V. Krotov, V.E. Zhukov, Instruments and Experimental Techniques 41(5), 727 (1998)

17. A.N. Pavlenko, V.E. Zhukov, N.I. Pecherkin, A.D. Nazarov, A.F. Serov, N.B. Miskiv, X. Li, B. Jiang, H. Sui, H. Li, X. Gao, Optoelectronics, Instrumentation and Data Processing 53, 19 (2017)

18. Chr. Boyadjiev, D. Dzhonova-Atanasova, P. Popova-Krumova, K.V. Stefanova, A.N. Pavlenko, V.E. Zhukov, E. Yu. Slesareva, Bulgarian Chem. Communications 52(F), 74 (2020)

19. Chr. Boyadjiev, Springer-Verlag Berlin Heidelberg 594 (2010)

20. A. Younes, N.E. Mohsen, Separation Science and Technology 54(15), 2536 (2018)

21. T. Petrova, Kr. Semkov, D. Dzhonova-Atanasova, Chem. Engin. Transactions 70, 2051 (2018)

22. B. Mahr, D. Mewes, Chem. Engin. Research and Design 85(8), 1112 (2007)

23. D. Dzhonova-Atanasova, T. Petrova, Kr. Semkov, S. Darakchiev, K. Stefanova, Sv. Nakov, R. Popov, Chem. Engin. Transactions 70, 2077 (2018) 